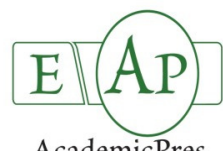

\title{
Romanian Wines Quality and Authenticity Using FT-MIR Spectroscopy Coupled with Multivariate Data Analysis
}

\author{
Roxana BANC ${ }^{1}$, Felicia LOGHIN², Doina MIERE ${ }^{1}$, \\ Florinela FETEA ${ }^{3}$, Carmen SOCACIU ${ }^{3 *}$ \\ ${ }^{1}$ University of Medicine and Pharmacy "Iuliu Hatieganu", Faculty of Pharmacy, Department of Bromatology, Hygiene, Nutrition, 6 Pasteur Street, \\ 400349 Cluj-Napoca, Romania; roxana.banc@umfcluj.ro; dmiere@umfcluj.ro \\ ${ }^{2}$ University of Medicine and Pharmacy "Iuliu Hatieganu", Faculty of Pharmacy, Department of Toxicology, 6 Pasteur Street, \\ 400349 Cluj-Napoca, Romania; floghin@umfcluj.ro \\ ${ }^{3}$ University of Agricultural Sciences and Veterinary Medicine, Faculty of Food Science and Technology, 3-5 Manastur St., \\ 400372 Cluj-Napoca, Romania; florinelafetea@yahoo.com; carmen.socaciu@usamvcluj.ro (*orresponding author)
}

\begin{abstract}
Fourier Transform Mid-Infrared Spectroscopy (FT-MIR) combined with multivariate data analysis have been applied for the discrimination of 15 different Romanian wines (white, rosé and red wines), obtained from different origin-denominated cultivars. Principal component analysis and hierarchical cluster analysis was performed using different regions of FT-MIR spectra for all wines. The general fingerprint of wines was splitted in four characteristic regions, corresponding to phenolic derivatives, carbohydrates, amino acids and organic acids, which confer the wines quality and authenticity. By qualitative and quantitative evaluation of each component category, it was possible to discriminate each wine category, from red, to rosé and white colours, to dry, half-dry and half-sweet flavours. The multivariate data analysis based on absorption peaks from FT-MIR spectra demonstrated a very good, significant clustering of samples, based on the four main components: phenolics, carbohydrates, amino acids and organic acids. Therefore, the ATR-FT-MIR analysis proved to be a very fast, cheap and efficient tool to evaluate the quality and authenticity of wines, and to discriminate each wine category, based on their colour and sweetness, as consequence of their biological (cultivar) specificity.
\end{abstract}

Keywords: carbohydrates and acidity, Fourier Transform Mid-Infrared Spectroscopy, phenolics, Principal Component Analysis, red, rosé and white wines

\section{Introduction}

Grapes, grape juices and wines, consumed in moderate quantities, proved to contain a large number of phytochemicals with health benefits promoting effects (German and Walzem, 2000), from essential amino acids, minerals, organic acids, aromas, stilbenes (resveratrol), vitamins, and especially a large variety of pigments (flavonoids and anthocyanins) as well catechins, procyanidins and phenolic acid derivatives (Jackson, 2008).

Therefore, the quality and authenticity of the varietal origin of grapes and wines is of great interest to both the wine industry and the consumer (Cozzolino et al., 2003; Cozzolino et al., 2009). The main secondary metabolites found in grapes, with important roles in plant resistance to pathogens, allelopathy, oxidative stress and plant growth regulation, are the phenolic derivatives (Ogbemudia and Thompson, 2014). These derivatives include monophenolic compounds (phenolic acids, as free or derivatized as esters or glucosides, e.g. benzoic and cinnamic acid derivatives), and especially polyphenolics (anthocyanins and flavonoids, catechins, procyanidins, and their derivatives) keybiomarkers of grapes and wines' quality, having antioxidant, antimutagenic, antiproliferative and antimicrobial properties (Guerrero et al., 2009). Phenolic acids are derived from benzoic and cinnamic acids and are found as free acids and esters, glycosides or bound complexes, which have also beneficial effects on human health (German and Walzem, 2000; Mateus et al., 2001; Socaciu, 2008).

The modern analytical methods to evaluate phenolic derivatives are usually based on reversed-phase highperformance liquid chromatography (HPLC), or another separation techniques such as gas chromatography or capillary electrophoresis, followed by ultraviolet (UV), electrochemical (EC), fluorescence (F) or mass spectrometric (MS) detection (Lorrain et al., 2013). Commonly, for wines direct analysis or solid-phase extraction followed by reversed phase HPLC-UV-VIS or HPLC-MS methods were used to analyze the phenolic 
557

fingerprint providing detailed information regarding individual phenolics and their quantity, enabling high resolution and accurate measurement of monomeric anthocyanins and catechins (Ginjom et al., 2011), but also the discrimination of cultivars (Muccillo et al., 2014), the influence of fermentation, vinification, maturation during storage, formation of oligomeric and polymeric pigments (García-Falcón et al., 2007; Ivanova et al., 2012). In spite of so many factors of influence, the differences in the overall quality of wines, their phenolic fingerprint still remains characteristic for each cultivar (Avar, 2007; Da Costa et al., 2000; Gruz et al., 2008).

In contrast to chromatography, spectroscopic techniques (UV-Vis, IR), when applied to mixtures, are less selective but may contain information about the complete phenolic composition of the wines under investigation (Gorinstein et al., 1992). UV-Vis spectrometry coupled with infrared spectroscopy, proved to be a cheap and rapid analytical method to be used for wine composition, quality and authenticity evaluation (Linskens and Jackson, 1988; Somers and Verétte, 1988).

The use of infrared (IR) spectroscopy for routine analysis of wine began with near infrared spectroscopy (NIRS) as preferred method in the early 1980's (Hashimoto and Kameoka, 2008; Ough and Amerine, 1988). Since that time, the focus for quantitative analysis of grapes and wine has moved towards Fourier transform infrared (FT-IR) technology in the mid-infrared region, since it offers better accuracy in determination and more constituents and properties can be quantified compared to NIRS (Dubernet and Dubernet, 2000; Eichinger et al., 2004; Patz et al., 2004; Soriano et al., 2007). Modern infrared spectroscopic instrumentation is fitted with chemometric software packages that facilitate the establishment of calibration models which can be used to quantify many components simultaneously, thereby reducing the analysis time and cost (Eichinger $e$ t al., 2004). FT-IR spectroscopy technology and chemometric techniques for analysis of grapes and wine were implemented in South Africa in the early 2000's (Bauer et al., 2008) and several qualitative and quantitative applications were developed in the last few years.

Near-infrared (NIR), as well as mid-infrared (MIR) spectroscopic techniques combined with multivariate data analysis, proved to be very promising for their good reproducibility in routine analysis (Irudayaraj and Tewari, 2003; Schulz and Baranska, 2007). While NIR absorptions reflect only overtones and combination bands of fundamental transitions, less distinct, the mid-infrared (MIR) absorption bands are related to defined vibrational transitions and are better resolved. The significant improvements in the IR instruments design and auxiliary optics have made modern MIR spectrometers robust for routine applications for liquids, MIR spectra being conveniently recorded using the attenuated total reflection (ATR) technique (Wilson and Tapp, 1999).

The Fourier Transform Infrared Spectroscopy (FT-IR) technique, in combination with chemometrics, is a fast and reproducible technique for identifying the authenticity and adulteration of different food and beverage products ( $\mathrm{Da}$ Costa et al., 2004). The FT-IR is increasingly used for the authentication of alcoholic beverages (Gallignani et al.,
2005; Kupina and Shrikhande, 2003) or to verify the authenticity of different fruit juices (Leopold et al., 2011).

During the last two decades, extended studies on grapes and wines were reported, using NIR and FT-IR coupled with biostatistical tools, either to evidentiate saccharides, alcohols or other quality parameters, or their authenticity and traceability, related to origin (cultivar or region) (Chedea et al., 2010; Coimbra et al., 2002; Da Costa et al., 2004; Edelmann et al., 2001; Edenharder et al., 2001; Orbán et al., 2006; Peña-Neira et al., 2000). Using the FTIR spectra of the wine polysaccharide (1200 and $800 \mathrm{~cm}^{-1}$ ) of the dry extracts coupled with PCA and CCA chemometric methods, it was possible to discriminate extracts based on the polysaccharide composition. Based on the bands from $1600 \mathrm{~cm}^{-1}$, the polyphenolic content was also evaluated (Gorinstein et al., 1992).

Mid-infrared spectroscopy and UV-Vis spectroscopy combined with multivariate data analysis have been applied also for the discrimination of different red wine cultivars ('Cabernet Sauvignon', 'Merlot', 'Pinot Noir', 'Blaufrankisch', 'St. Laurent', and 'Zweigelt'). Both authentic wines and their phenolic extracts were investigated by ATR-MIR spectroscopy and UV-Vis spectroscopy (Edelmann et al., 2001). The main components (sugar and organic acids) failed to offer satisfactory classification of wines, but by using phenolic extracts, a complete discrimination of all cultivars investigated was achieved.

The FT-IR spectra were also used for the differentiation and classification of wines and brandies during their ageing process, as well as for the characterization and differentiation of distilled drinks from several countries (Palma and Barroso, 2002), good linear regression coefficients (0.995) between the ageing scale and the FT-IR data being obtained (Eichinger $e t$ al., 2004).

The oenological wine parameters (alcoholic degree, volumic mass, total acidity, glycerol, total polyphenol index, lactic acid and total sulphur dioxide) were investigated by combined NIRS and FT-MIRS. In this case, NIRS yielded better results, but the use of both methods improved the determination of glycerol and total sulphur dioxide. The validation sets used for developing general equations were built with samples from different "apellation d'origine" (Urbano Cuadrado et al., 2005).

A fast and accurate study was reported on 22 Romanian red wines of 'Cabernet Sauvignon', 'Merlot', 'Fetească Neagră', 'Pinot Noir' and 'Burgund' varieties, comparing 1H-NMR with the IR spectroscopy (Todasca et al., 2007). By IR spectroscopy, characteristic bands for amino acids $\left(1604 \mathrm{~cm}^{-1}\right)$ and organic acids $\left(1719 \mathrm{~cm}^{-1}\right)$ were investigated, but the method could not provide good differentiations. Meanwhile, the NMR method is considered to be more accurate, but much more expensive.

This study aims to investigate the use of mid-infrared (MIR) and multivariate data analysis techniques to classify Romanian wines produced from autochthonous cultivars. In this respect, the Fourier Transform mid-infrared (FTMIR) spectroscopy was applied to characterize 15 different Romanian wines (white, rosé and red wines), obtained from different authentic, origin-denominated cultivars, found in different Romanian regions. The wines were investigated by 
attenuated total reflectance (ATR) and the most important components (phenolics, carbohydrates, amino acids and organic acids) were localized in specific fingerprint regions of the spectra. Based on the differences between the FTMIR spectra, by multivariate data analysis (Principal component analysis), were identified the specific discrimination factors useful to authenticate the biological (cultivar) and regional origin, as well their sweetness index.

\section{Materials and methods}

\section{Wine samples}

Fifteen Romanian wines, including white $(n=4)$, rosé $(n=2)$ and red $(n=9)$, of different sweetness indexes ( 5 samples dry, 7 samples half-dry and 3 samples half-sweet) were investigated. These wines originated from different cultivars and were produced in ten different wineries from Romania, namely Jidvei, Coteşti, Panciu, Huşi, Recaş, Ceptura, Tohani, Sarica-Niculitel, Murfatlar, and Sadova Corabia. The wines, packed in glass bottles and produced in the vintage years 2008-2012, were purchased from local supermarkets and stored at room temperature until analyzed. Tab. 1 includes data from each wine sample, the specific cultivar, the year of production and the denomination (as dry, half-dry, half-sweet) and their region of origin. All wine samples were centrifuged at 3000 $\mathrm{rot} / \mathrm{min}$ for $15 \mathrm{~min}$, then used directly for recording the FTMIR spectra.

Tab. 1. Numbering of wine samples: white (1-4), rosé (5-6), red (7-15) with references to the sweetness index (dry, half-dry, half-sweet) and the production year

\begin{tabular}{|c|c|c|c|c|}
\hline No. & Cultivar (Variety) & Vineyard & Year & Wine type \\
\hline \multicolumn{5}{|c|}{ White wine } \\
\hline 1 & Feteasca Alba & Cotesti & 2011 & Half-dry \\
\hline 2 & Feteasca Alba & Jidvei & 2011 & Dry \\
\hline 3 & Feteasca Regala & Jidvei & 2011 & Half-dry \\
\hline 4 & Feteasca Regala & Recas & 2012 & Half-dry \\
\hline \multicolumn{5}{|c|}{ Rosé wine } \\
\hline 5 & Babeasca Rose & Panciu & 2012 & Half-dry \\
\hline 6 & Busuioaca de Bohotin & Husi & 2011 & Half-sweet \\
\hline \multicolumn{5}{|c|}{ Red wine } \\
\hline 7 & Babeasca Neagra & Panciu & 2012 & Half-dry \\
\hline 8 & Babeasca Neagra & Husi & 2009 & Dry \\
\hline 9 & Babeasca Neagra & Sarica-Niculitel & 2011 & Dry \\
\hline 10 & Babeasca Neagra & Sadova Corabia & 2010 & Dry \\
\hline 11 & Feteasca Neagra & Cotesti & 2008 & Half-sweet \\
\hline 12 & Feteasca Neagra & Panciu & 2011 & Half-dry \\
\hline 13 & Feteasca Neagra & Ceptura & 2012 & Dry \\
\hline 14 & Feteasca Neagra & Tohani & 2010 & Half-dry \\
\hline 15 & Feteasca Neagra & Murfatlar & 2011 & Half-sweet \\
\hline
\end{tabular}

Fourier Transform Mid-Infrared (FT-MIR) Spectroscopy

The FT-IR spectra were obtained with a Shimadzu IR Prestige-21 spectrometer including a HATR device and an internal reflection accessory (10 reflections) made of Zinc Selenide $(\mathrm{ZnSe})$. The samples were recorded by co-adding 64 scans. Each spectrum was registered from $3500-600 \mathrm{~cm}^{-P}$. As reference, the background spectrum of air was collected. The total phenolic extracts' contents were measured without any preparation, directly on the ZnSe ATR (Attenuated Total Reflection) crystal. Between measurements, the ATR crystal was carefully cleaned using acetone.

\section{Multivariate data analysis}

Advanced chemometrics was applied to discriminate between different wine samples, based on their colour, content of phenolic derivatives, amino acids and organic acids, as well as carbohydrates. Therefore, the discrimination was performed using the whole FT-MIR spectra (600-3500 $\left.\mathrm{cm}^{-1}\right)$ as well as the regions identified (1-4) at frequencies of $600-940 \mathrm{~cm}^{-1}$ (1), 970-1100 $\mathrm{cm}^{-1}$ (2), 1600-1716 cm $\mathrm{cm}^{-1}$ (3) and $2800-3000 \mathrm{~cm}^{-1}(4)$. To discriminate among these samples and regions, the principal component analysis (PCA) was applied on the peak areas corresponding to each region, using Unscrambler X 10.1 Software, version 10.1.

The correlation factors were calculated using Origin software (OriginLab, version 8.0).

\section{Results and discussion}

\section{FT-MIR spectral fingerprinting of individual wine} samples

Fig. 1 exhibits the general FT-MIR spectra of all wine samples, from white (samples no. 1-4), to rosé (samples no. $5,6)$ and red wines (samples no. 7-15), according to their list in Tab. 1 in the whole IR region range, from 600 to 3500 $\mathrm{cm}^{-1}$. In all samples, similar spectral features were generally obtained, but with specific quantitative modifications in the fingerprint region $\left(1800-600 \mathrm{~cm}^{-1}\right)$. Comparing the shapes of spectra, there were identified four different regions (1-4) which can show specific differences, related to the colour of wines (white, rosé and red wines), and to the sweetness (dry $v$ s half-dry and half-sweet).

Tab. 2 includes the specific wave numbers and fingerprint regions used to identify the stretching and bending vibrations, depending on the functional groups, as reported in literature (Coimbra et al., 2002; Gorinstein et al., 1992; Todasca et al., 2007). Such data were useful in the interpretation of the FT-MIR absorption peaks obtained in

Tab. 2. Characteristic IR wave numbers $\left(\mathrm{cm}^{-1}\right)$ for stretching and bending vibrations in wines, according to literature reports (Coimbra $e t$ al., 2002; Gorinstein et al., 1992; Todasca et al., 2007)

\begin{tabular}{|c|c|c|}
\hline $\begin{array}{l}\text { Fingerprint } \\
\text { regions } \\
\left(\mathrm{cm}^{-1}\right)\end{array}$ & $\begin{array}{l}\text { Characteristic } \\
\text { frequencies } \\
\quad\left(\mathrm{cm}^{-1}\right)\end{array}$ & Assignment \\
\hline$<1000$ & $\begin{array}{c}690,745,961 \\
964\end{array}$ & $\begin{array}{l}\text { Phosphates, Phenolics, Mono-substituted } \\
\text { phenyl derivatives, Unsaturated lipids, } \\
\text { incl. carotenoids }\end{array}$ \\
\hline $970-1100$ & $\begin{array}{c}976,1030 \\
1060,1065 \\
1079\end{array}$ & $\begin{array}{l}\text { Glucose, Oligo- and polysaccharides, incl. } \\
\text { metoxylated derivatives } \\
\text { Alcohols (ethanol) }\end{array}$ \\
\hline $1500-1716$ & $\begin{array}{l}1566,1574 \\
1650,1662 \\
1655,1700\end{array}$ & $\begin{array}{l}\text { Organic acid stretching vibrations at } \\
\qquad 1700 \mathrm{~cm}^{-1} \\
\text { Amide I, II } \\
\text { Aromatic ring stretching at } 1600 \mathrm{~cm}^{-1} \\
\text { Stretching vibrations of Amino acids and } \\
\text { their derivatives at } 1530-1600 \mathrm{~cm}^{-1} \\
\text { Esters and flavours } 1715 \mathrm{~cm}^{-1}\end{array}$ \\
\hline $2800-2935$ & $\begin{array}{c}2854,2920 \\
2934\end{array}$ & $\begin{array}{c}\text { Fatty acids, Polyols (glycerol), Free } \\
\text { phenolic acids and catechins, } \\
\text { Cholesterol, Carotenoid pigments }\end{array}$ \\
\hline $3300-3500$ & & $\begin{array}{l}\text { OH stretching from water and other } \\
\text { hydroxylated molecules (alcohols and } \\
\text { phenols) }\end{array}$ \\
\hline
\end{tabular}




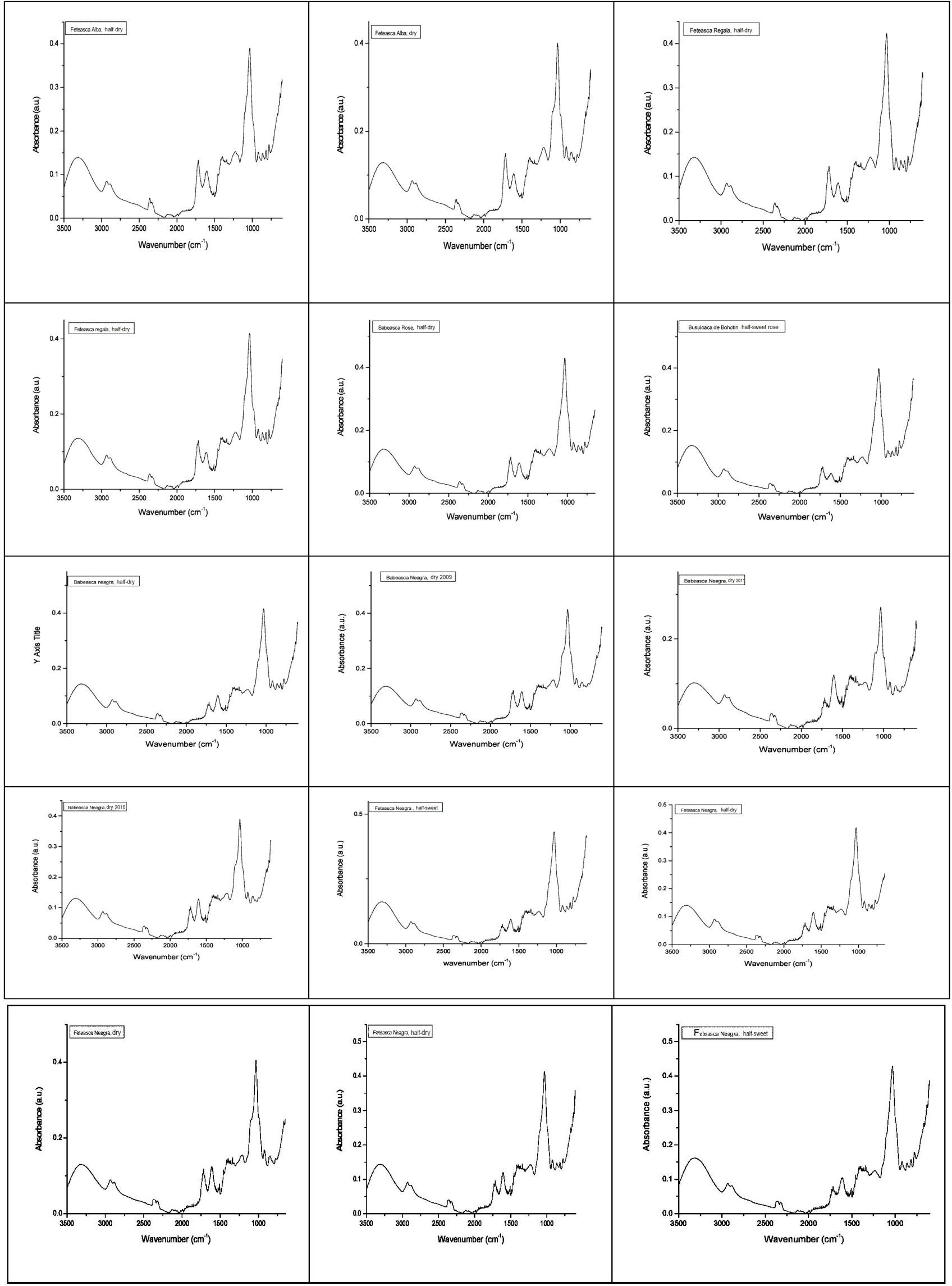

Fig. 1. Individual FT-MIR spectra registered for all 15 wine samples, in the region $600-3500 \mathrm{~cm}^{-1}$ 
all wine spectra. The region $750-900 \mathrm{~cm}^{-1}$ corresponds to absorptions of phenyl/aromatic derivatives, including phenolics. Aromatic derivatives have also $\mathrm{OH}$ - stretching bands between $1200-1250 \mathrm{~cm}^{-1}$. The region $1030-1100 \mathrm{~cm}^{-}$ ${ }^{1}$ is specific to absorptions of - $\mathrm{C}-\mathrm{OH}$ groups found in carbohydrates, e.g. $1030 \mathrm{~cm}^{-1}$ for glucose and $1060 \mathrm{~cm}^{-1}$ for fructose (Leopold et al., 2009). Amino acids like proline, alanine, arginine, glutamic acid, $\gamma$-aminobutiric acid absorb at $1608 \mathrm{~cm}^{-1}$ and simple phenolics like gallic acid and catechins absorb around $1600 \mathrm{~cm}^{-1}$. The absorption band at $1716 \mathrm{~cm}^{-1}$ is characteristic to organic acids found in wines (tartaric, acetic, lactic, citric, malic acids). The absorption band at $2938 \mathrm{~cm}^{-1}$ is usually related to polyols, like glycerol and other compounds like flavours. Generally, wines contain water, alcohols, glycerol, sorbitol, mannitol, amino acids, esters, minerals, sulfites, phenols, sugars, organic acids such as tartaric, malic and citric acids, aldehydes, as well as volatile acids as common ingredients (Cerdán et al., 2004). Similarity of the most important components gave rise to similar peak positions in the FT-IR spectra of the studied Romanian wines.

\section{Identification of specific functional groups and molecules in} wines, depending on their colour and sweetness

According to Fig. 2, representing a generic FT-MIR spectra of wines, it was possible to consider 4 specific regions which can be useful for wines' characterization: region 600$940 \mathrm{~cm}^{-1}$ (1) corresponds to phenolics derivatives (including esters), region $2\left(970-1100 \mathrm{~cm}^{-1}\right)$ to carbohydrates (glucose, fructose and oligosaccharides, mainly saccharose), region 3 $\left(1600-1716 \mathrm{~cm}^{-1}\right)$ to free amino acids, peptides and organic acids and region 4 (2800-3000 $\left.\mathrm{cm}^{-1}\right)$ for polyols (mainly glycerol). Tab. 3 includes the FT-MIR absorption wave numbers, specific to the 4 regions of each wine fingerprinting: $600-940 \mathrm{~cm}^{-1}(1), 970-1100 \mathrm{~cm}^{-1}(2), 1600-$ $1700 \mathrm{~cm}^{-1}(3)$. In the $4^{\text {th }}$ region $\left(2800-3000 \mathrm{~cm}^{-1}\right)$, all wines absorbed at the same wave numbers, 2887 and $2931 \mathrm{~cm}^{-1}$. Generally, the range $600-1800 \mathrm{~cm}^{-1}$ was considered as "fingerprint region", useful to differentiate wines according to their sweetness index (dry $v s$ half-dry and half-sweet). One can notice that in region 1 , the absorptions are determined mainly by the polyphenols, region 2 was specific to carbohydrates, mainly glucose $\left(1033 \mathrm{~cm}^{-1}\right)$, but also fructose and sucrose $\left(1100 \mathrm{~cm}^{-1}\right)$; region 3 was specific to amino acids $\left(1602-1608 \mathrm{~cm}^{-1}\right)$ and organic acids $\left(1700 \mathrm{~cm}^{-1}\right)$.

FT-IR spectra of wines showed absorption bands at different frequencies and these bands can be attributed to the various functional groups. IR spectral peaks are related to the bonds in the compounds, thus they could be assigned to the composition of the specific food sample such as its phenol, alcohol, aldehyde, higher alcohol, polyol, acid, sugar, volatile acid and amino acid content (Lee et al., 2009).

Tab. 4 shows detailed information regarding the values of peak intensities at $1033,1100,1600,1700 \mathrm{~cm}^{-1}$, which can be used as quantitative markers of differences between the individual wines and wine types (based on colour and sweetness index). The ratios $1033 / 1100 \mathrm{~cm}^{-1}$ and $1600 / 1700 \mathrm{~cm}^{-1}$ were also used to characterize quantitatively the sweetness claimed on the label of these wines (dry, half-dry and half-sweet). Fig. 3 represents the differences between mean values registered from peak intensities corresponding to glucose $(\mathrm{G})$, fructose+ sucrose $(\mathrm{F}+\mathrm{S})$, amino acids (AA) and organic acids (OA). Characteristic absorbance peaks of sugar components (970$1100 \mathrm{~cm}^{-1}$ ) as well as amino acids and organic acids (1600-

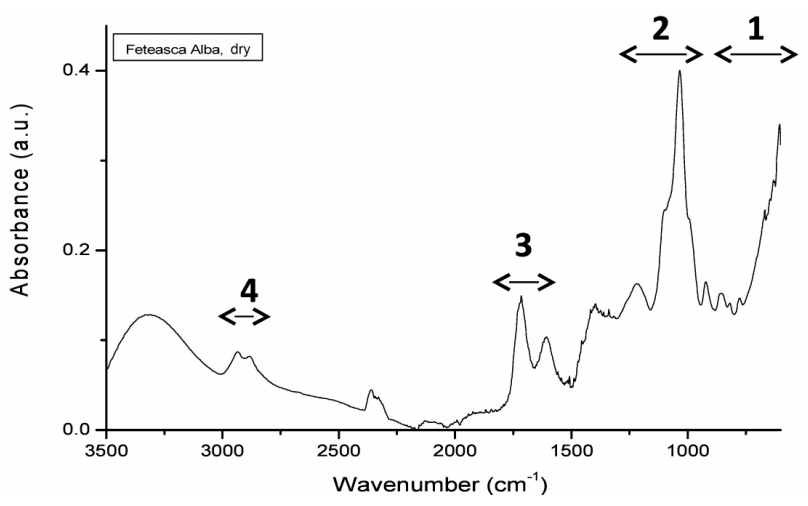

Fig. 2. The FT-MIR spectra of a wine sample: 1 - spectral region $600-940 \mathrm{~cm}^{-1} ; 2$ - spectral region $970-1100 \mathrm{~cm}^{-1} ; 3$ spectral region $1600-1716 \mathrm{~cm}^{-1} ; 4$ - spectral region $2800-3000$ $\mathrm{cm}^{-1}$

Tab. 3. FT-MIR absorption wave numbers specific to the 4 regions of each wine fingerprinting: $600-940 \mathrm{~cm}^{-1}(1), 970-1100 \mathrm{~cm}^{-1}(2), 1600-1700 \mathrm{~cm}^{-1}$

(3). In the $4^{\text {th }}$ region $\left(2800-3000 \mathrm{~cm}^{-1}\right)$, all wines absorbed at the same wave numbers, 2887 and $2931 \mathrm{~cm}^{-1}$

\begin{tabular}{cccc}
\hline Wine no. & $1\left(600-940 \mathrm{~cm}^{-1}\right)$ & $2\left(970-1100 \mathrm{~cm}^{-1}\right)$ & $3\left(1600-1700 \mathrm{~cm}^{-1}\right)$ \\
\hline 1 & $630,777,817,864,920$ & 1033 & 1602,1716 \\
2 & $775,817,854,921$ & 1033 & 1608,1716 \\
3 & $605,667,777,817,862,920$ & 1031 & 1602,1716 \\
4 & $630,779,817,864,921$ & 1033 & 1602,1716 \\
5 & $603,775,817,860,920$ & 1031 & 1608,1716 \\
6 & $630,775,815,864,898,898$ & 1028 & 1602,1716 \\
7 & $603,630,775,817,862,920$ & 1033 & 1608,1716 \\
8 & $605,630,775,817,923$ & 1033 & 1602,1716 \\
9 & $771,854,923,995$ & 1033 & 1608,1716 \\
10 & $771,854,923$ & 1033 & 1602,1716 \\
11 & $775,815,862,920$ & 1033 & 1608,1716 \\
12 & $603,775,815,862,921$ & 1033 & 1602,1716 \\
13 & $607,630,775,854,921$ & 1033 & 1608,1716 \\
15 & $605,775,817,862,921$ & 1033 & 1602,1716 \\
\hline
\end{tabular}


561

Tab. 4. Peak intensities which can be used as quantitative markers of differences between the individual wines and wine types (based on colour and sweetness index)

\begin{tabular}{cccccccc}
\hline $\begin{array}{c}\text { Wine } \\
\text { no. }\end{array}$ & $\begin{array}{c}1033 \mathrm{~cm}^{-1} \\
\text { (glucose) }\end{array}$ & $\begin{array}{c}1100 \mathrm{~cm}^{-1} \\
\text { (fructose and } \\
\text { sucrose) }\end{array}$ & $1033 / 1100$ & $\begin{array}{c}1600 \mathrm{~cm}^{-1} \\
(\text { amino acids })\end{array}$ & $\begin{array}{c}1700 \mathrm{~cm}^{-1} \\
\text { (organic acids) }\end{array}$ & $1600 / 1700$ & Wine type \\
\hline 1 & 0.3901 & 0.246 & 1.5858 & 0.1081 & 0.1332 & 0.812 & Half-dry \\
2 & 0.4006 & 0.242 & 1.6554 & 0.1038 & 0.1494 & 0.695 & Dry \\
3 & 0.4233 & 0.2387 & 1.7734 & 0.0853 & 0.1223 & 0.697 & Half-dry \\
4 & 0.4142 & 0.2534 & 1.6346 & 0.0986 & 0.1299 & 0.759 & Half-dry \\
5 & 0.43052 & 0.2378 & 1.8104 & 0.0974 & 0.1151 & 0.846 & Half-dry \\
6 & 0.3978 & 0.2125 & 1.8720 & 0.0633 & 0.0854 & 0.741 & Half-sweet \\
7 & 0.4154 & 0.2265 & 1.8340 & 0.1018 & 0.0777 & 1.310 & Half-dry \\
8 & 0.414 & 0.2495 & 1.6593 & 0.1163 & 0.1206 & 0.964 & Dry \\
9 & 0.2714 & 0.169 & 1.6059 & 0.1192 & 0.0685 & 1.740 & Dry \\
10 & 0.3903 & 0.2388 & 1.6344 & 0.1290 & 0.1045 & 1.235 & Dry \\
11 & 0.4318 & 0.2347 & 1.8398 & 0.0952 & 0.0765 & 1.244 & Half-sweet \\
12 & 0.4183 & 0.2345 & 1.7838 & 0.1163 & 0.0785 & 1.481 & Half-dry \\
13 & 0.4039 & 0.2518 & 1.6041 & 0.1237 & 0.1183 & 1.045 & Dry \\
14 & 0.4135 & 0.2385 & 1.7338 & 0.1196 & 0.0955 & 1.252 & Half-dry \\
15 & 0.4282 & 0.2291 & 1.8691 & 0.1044 & 0.0790 & 1.322 & Half-sweet \\
\hline $\begin{array}{c}\text { Mean values } \\
\text { (MV) }\end{array}$ & 0.4028 & 0.2335 & 1.7263 & 0.1054 & 0.1036 & 1.0762 & \\
\hline
\end{tabular}

$1716 \mathrm{~cm}^{-1}$ ) appeared and the intensity of these peaks increased with the increase of sugar and acid content. Thus, according to the characteristic peaks in the infrared spectra in the range of $970-1100 \mathrm{~cm}^{-1}$ and $1600-1716 \mathrm{~cm}^{-1}$, dry, halfdry and half-sweet wines can be divided according to the amount of sugar, amino acids and organic acids, that can be evaluated in accordance with such spectra. Tarantilis et al. (2008) also reported differentiation between wine samples based on small differences between spectra of their phenolic extracts, the spectral region between $1800-900 \mathrm{~cm}^{-1}$ being chosen for wine fingerprinting. Also, Chen et al. (2009) have achieved discrimination between dry and sweet red wine samples using $2 \mathrm{D}$ correlation spectroscopy and MIR.

\section{Multivariate Data Analysis by Principal Component Analysis}

PCA was performed on the MIR spectra, to examine qualitative differences within the set of red, rosé and white wines. Figs. 4-7 present the results of PCA analysis and



Fig. 3. Mean values of peak intensities registered for: glucose, fructose and sucrose $(\mathrm{F}+\mathrm{S})$, amino acids $(\mathrm{AA})$ and organic acids (OA). Abbreviations: MV-mean value; D-dry, HD-halfdry; HS-half-sweet; W-white; Ro-rosé scoring, to discriminate between wine types, based on the general FT-IR fingerprint (Fig. 4, from 600 to $1800 \mathrm{~cm}^{-1}$ ) considering as well the three regions of IR absorption specific to phenolic derivatives (Fig. 5, 750-940 $\mathrm{cm}^{-1}$ ), carbohydrate derivatives (Fig. 6, 970-1100 $\mathrm{cm}^{-1}$ ) and amino acids and organic acids (Fig. 7, 1600-1716 $\mathrm{cm}^{-1}$ ).

As presented in Fig. 4, for the whole fingerprint region, the first principal component (PC1) explained $68 \%$ of the variability and the second principal component (PC2) explained $22 \%$ of the variability; while together PC1 and PC2 explained 90\% of the whole variability of wine samples and showed a good similarity for white wines (grouped in the positive quadrate), also for rosé wines (close in the inferior quadrate). Red wines were more heterogeneous in the composition and were spread, not clustered in a specific group. Nevertheless, the red, half-sweet wines (11 and 15) were close to the rosé wines, which proved to be superior in sweetness.

As presented in Fig. 5, for the region 750-940 $\mathrm{cm}^{-1}$, specific to phenolic derivatives, the first two components

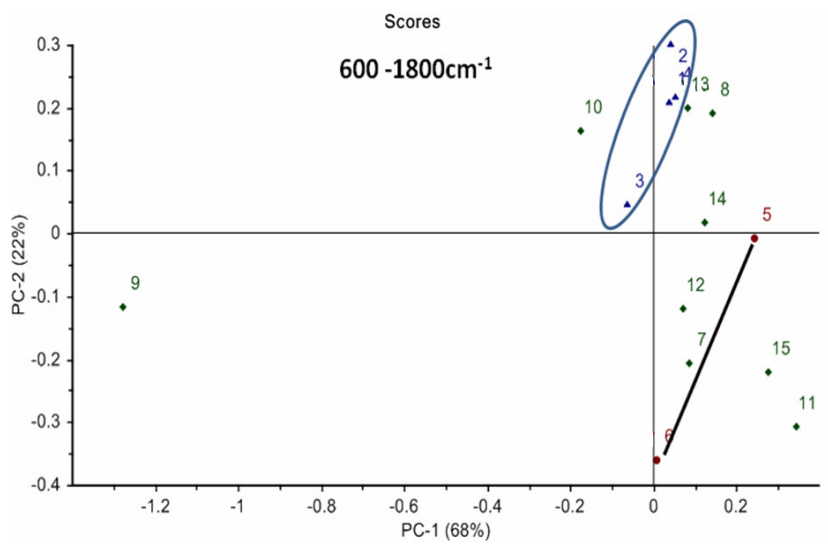

Fig. 4. The PCA scoring to discriminate between wine types, based on the FTIR fingerprint region $\left(600-1800 \mathrm{~cm}^{-1}\right)$. Sample numbering as in Tab. 1 
(PC1 and PC2) together, explained 98\% of the whole variability of wine samples. Although the variance explained was high (98\%), a weaker clustering of wines based on their different colours was obtained. In this case, the wines were discriminated along the axis $\mathrm{PC} 2$, depending on the type of wine to which they belong (white, rosé or red), the three groups being partially overlapped with each other. Such overlaps are due to the closer relationship between some of wines which come from the same vineyard (eg, sample no. 1 overlapped red wines, close to the sample no. 11) or the same manufacturer (eg, sample no. 5 overlapped red wines, close to the samples no. 7 and 12). A weaker clustering of wines can also be explained by the fact that PCA is sensitive to the number of samples in the data set and it requires relative equality in group sizes to adequately discriminate between groups with very similar characteristics (Bevin et al., 2008).

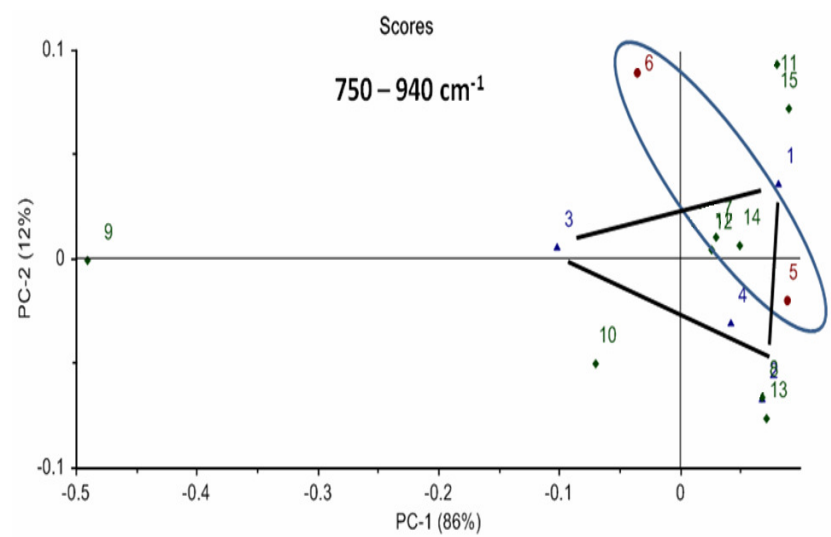

Fig. 5. The PCA scoring to discriminate between wine types, based on the FTIR fingerprint region specific to phenolic derivatives $\left(750-940 \mathrm{~cm}^{-1}\right)$. Sample numbering as in Tab. 1

Fig. 6, representing the scores for the region 970-1100 $\mathrm{cm}^{-1}$, specific to carbohydrates derivatives, revealed an excellent clustering of wines, not only based on colour, but especially considering their sweetness index, excepting wine no. 9. The first principal component (PC1) explained 90\% of the variability and the second principal component (PC2) explained 7\% of the variability; together, PC1 and PC2 explained $97 \%$ of the whole variability of wine samples.

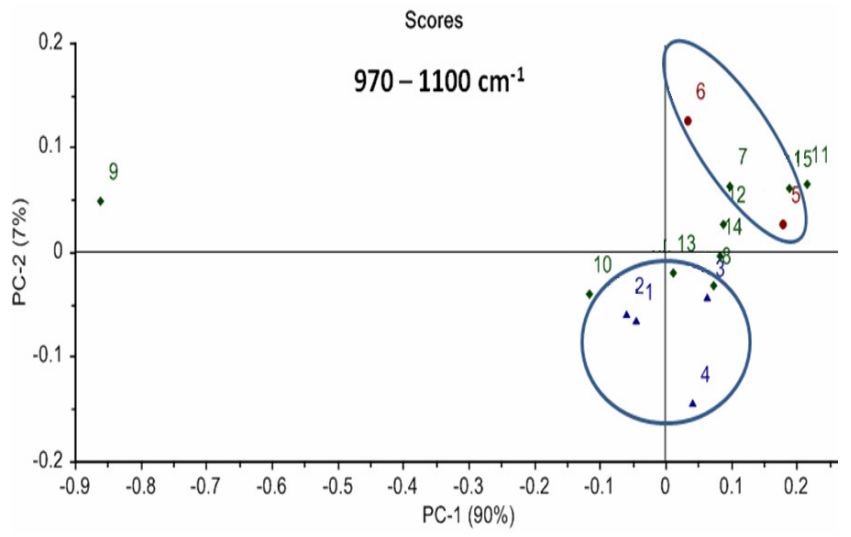

Fig. 6. The PCA scoring to discriminate between wine types, based on the FTIR fingerprint region specific to carbohydrate derivatives $\left(970-1100 \mathrm{~cm}^{-1}\right)$. Sample numbering as in Tab. 1

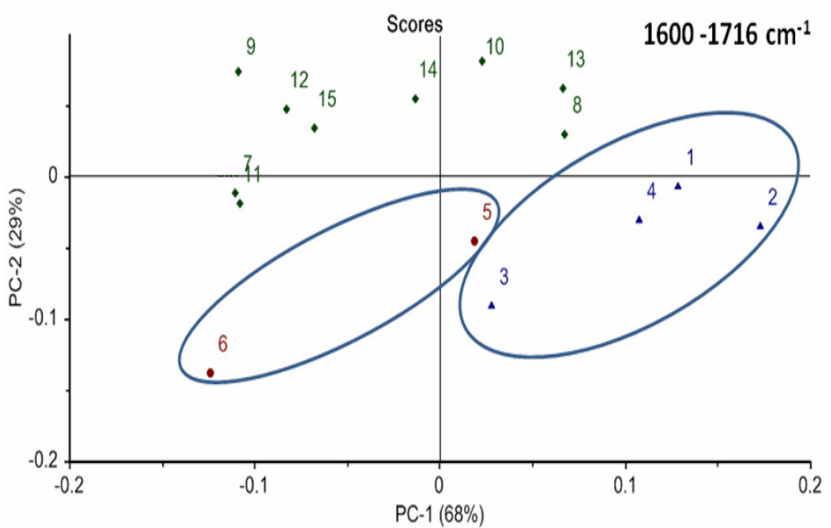

Fig. 7. The PCA scoring to discriminate between wine types, based on the FTIR fingerprint region specific to amino acids and organic acids derivatives (1600-1716 $\left.\mathrm{cm}^{-1}\right)$. Sample numbering as in Tab. 1

Fig. 7 represents the scores for the region 1600-1716 $\mathrm{cm}^{-1}$, specific to amino acids and organic acids derivatives. In this case, the first principal component (PC1) explained $68 \%$ of the variability and the second principal component (PC2) explained $29 \%$ of the variability, together PC1 and PC2 explaining $97 \%$ of the whole variability of wine samples and suggesting a good clustering based on acidity. Thus, we can notice higher PC1 values for white wines (samples no. 1-4, clustered in the positive quadrate of PC1 and negative quadrate of PC2), followed by rosé wines (samples no. 5-6, clustered in the negative quadrates of both $\mathrm{PC} 1$ and PC2), being more acidic, compared with red wines, less clustered and located all along the first axis (PC1), in the upper part of the plot, in the positive quadrates of PC1 and PC2. Interestingly, samples no. 8, 10, 13, excepting 9, were more acidic, belonging to the dry wines category.

The combination of MIR and chemometric techniques presented in this study allowed almost complete discrimination between samples. Although some samples did overlap, generally, a separation was observed between samples, according to their colour and sweetness index, which demonstrates that the high information content of MIR spectra has been used successfully for the fast classification of different types of wine. The ability of the MIR model to discriminate or identify wine samples was based on the vibrational responses of chemical bonds to MIR radiation (Cozzolino et al., 2009). As has been reported before by Zhang et al. (2010), using PCA as preprocessing method, dry and sweet wine samples can be classified correctly. The same authors suggested that the identification of glycerol, carboxylic acids or esters by MIR spectra analysis could serve to discriminate the different manufacturers and evaluate the quality of wine samples. Also, Cozzolino et al. (2009) have managed to achieve discrimination, within a set of red and white Australian wines, according to the two production systems (organic $v$ s non-organic), although some samples were overlapped. In contrast, Bevin et al. (2008) have not succeeded to adequately discriminate 73 white wines belonging to different varieties, by means of the PCA score plot.

Finally, we can point out that multivariate data analysis showed that all four components of wines (phenolics, 
563

carbohydrates, amino acids, organic acids) which contribute to the colour, sweetness and acidity, are responsible for the good, significant clustering of these wines. Although some of the wines were of the same variety, they came from different manufacturers; therefore, the PC plots of FT-IR data showed that the components of these wines are different and wines are clustered in their own individual groups, based on the colour and sweetness, and are apparently differentiated by their geographical origin.

\section{Conclusion}

This study has demonstrated that mid-infrared spectroscopy, coupled with principal component analysis represents a very powerful tool for distinguishing groups that have very similar properties, but have consistent overall differences, and might be used as a technique for the discrimination between different red, rosé and white wine varieties.

The results suggested that mid-infrared spectroscopy is an overall and effective method that offers the possibility to evaluate the authenticity of wines, without the need for costly and laborious chemical analysis.

The use of this fast technique can offer benefits for the wine industry by being a robust rapid screening tool for the discrimination of different types of wine, based on their colour and sweetness, and also being capable of measuring wine quality and assuring consumers of the quality of the final product to be enjoyed.

\section{References}

Avar P (2007). Investigation of phenolic components of Hungarian wine. Int J Mol Sci 8(10):1028-1038.

Bauer R, Nieuwoudt HH, Bauer FF, Kossmann J, Koch KR, Esbensen KH (2008). FTIR Spectroscopy for grape and wine analysis. Anal Chem 80(5):1371-1379.

Bevin CJ, Dambergs RG, Fergussona AJ, Cozzolino D (2008). Varietal discrimination of Australian wines by means of midinfrared spectroscopy and multivariate analysis. Anal Chim Acta 621:19-23.

Cerdán TG, Goñi DT, Azpilicueta CA (2004). Accumulation of volatile compounds during ageing of two red wines with different composition. J Food Eng 65(3):349-356.

Chedea V, Echim C, Braicu C, Andjelkovic M, Verhe R, Socaciu $C$ (2010). Composition in polyphenols and stability of the aqueous grape seed extract from the Romanian variety Merlot Recas.J Food Biochem 35(1):92-108.

Chen J, Zhou Q, Noda I, Sun S (2009). Quantitative classification of two-dimensional correlation spectra. Appl Spectrosc 63(8):920-925.

Coimbra MA, Gonçalves F, Barros AS, Delgadillo I (2002). Fourier transform infrared spectroscopy and chemometric analysis of white wine polysaccharide extracts. J. Agric Food Chem 50(12):3405-3411.

Cozzolino D, Smyth HE, Gishen M (2003). Feasibility study on the use of visible and near infrared spectroscopy to discriminate between white wine of different varietal origin. J Agric Food Chem 52:7701-7711.
Cozzolino D, Holdstock M, Dambergs RG, Cynkar WU, Smith PA (2009). Mid infrared spectroscopy and multivariate analysis: A tool to discriminate between organic and nonorganic wines grown in Australia. Food Chem 116:761-765.

Da Costa CT, Horton, D, Margolis SA (2000). Analysis of anthocyanins in foods by liquid chromatography, liquid chromatography-mass spectrometry and capillary electrophoresis. J Chromatogr A 881:403-410.

Da Costa RS, Santos SRB, Almeida LF, Nascimento ECL, Márcio JC, Pontes MJC, Lima RAC, Simões SS, Araújo MCU (2004). A novel strategy to verification of adulteration in alcoholic beverages based on Schlieren effect measurements and chemometric techniques. Microchem J 78(1):27-33.

Dubernet M, Dubernet M (2000). [Using infrared Fourier transform analysis for the routine wine analysis, (in French)]. Rev Fr d'OEnol 181:10-13.

Edelmann A, Diewok J, Schuster KC, Lendl B (2001). Rapid method for the discrimination of red wine cultivars based on mid-infrared spectroscopy of phenolic wine extracts. J Agric Food Chem 49(3):1139-1145.

Edenharder R, Keller G, Platt KL, Unger KK (2001). Isolation and characterization of structurally novel antimutagenic flavonoids from spinach (Spinacia oleracea). J Agric Food Chem 49(6):2767-2773.

Eichinger P, Holdstock M, Janik L (2004). Faster routine wine laboratory analysis using FT-IR. Tech Rev 151:72-74.

Gallignani M, Ayala C, Brunetto MD, Burguera JL, Burguera M (2005). A simple strategy for determining ethanol in all types of alcoholic beverages based on its on-line liquid-liquid extraction with chloroform, using a flow injection system and Fourier transform infrared spectrometric detection in the mid-IR. Talanta 68(2):470-479.

García-Falcón MS, Pérez-Lamela C, Martínez-Carballo E, SimalGándara J (2007). Determination of phenolic compounds in wines: Influence of bottle storage of young red wines on their evolution. Food Chem 105:248-259.

German JB, Walzem RL (2000). The health benefits of wine. Annu Rev Nutr 20:561-93.

Ginjom I, D’Arcy B, Caffin N, Gidley M (2011). Phenolic compound profiles in selected Queensland red wines at all stages ofthe wine-making process. Food Chem 125:823-834.

Gorinstein S, Moshe R, Deutsch J, Wolfed FH, Tilis K, Stiller A, Flam I, Gat Y (1992). Determination of basic components in white wines by HPLC, FT-IR spectroscopy, and electrophoretic techniques. J Food Compos Anal 5:236-245.

Gruz J, Novák O, Strnad M (2008). Rapid analysis of phenolic acids in beverages by UPLC-MS/MS. Food Chem 111(3):789-794.

Guerrero RF, García-Parrilla MC, Puertas B, Cantos-Villar E (2009). Wine, resveratrol and health: a review. Nat Prod Commun 4(5):635-658.

Hashimoto A, Kameoka T (2008). Applications of infrared spectroscopy to biochemical, food, and agricultural processes. Appl Spectrosc Rev 43(5):416-451. 
Irudayaraj J, Tewari J (2003). Simultaneous monitoring of organic acids and sugars in fresh and processed apple juice by Fourier transform infrared-attenuated total reflection spectroscopy. Appl Spectrosc 57(12):1599-1604.

Ivanova V, Vojnoski B, Stefova M (2012). Effect of winemaking treatment and wine aging on phenolic content in Vranec wines. J Food Sci Technol 49(2):161-172.

Jackson RS (2008). Chemical constituents of grapes and wine, p. 270-331. In: Jackson RS (Ed.). Wine Science: Principles and Applications. 3rd Edition, Academic Press, San Diego, CA.

Kupina SA, Shrikhande AJ (2003). Evaluation of a Fourier transform infrared instrument for rapid quality-control wine analysis. Am J Enol Vitic 54(2):131-134.

Lee VS, Tue-ngeun P, Traisathit P, Prasitwattanaseree S, Nimmanpipug P, Chaijaruwanich J (2009). FTIR and chemometric tools for the classification of Thai wines. Maejo Int J Sci Technol 3(03):446-458.

Leopold L, Diehl HA, Socaciu C (2009). Quantification of glucose, fructose and sucrose in apple juices using ATR-MIR spectroscopy coupled with chemometry. Bulletin UASMV Agriculture 66(2): 350-357.

Leopold LF, Leopold N, Diehl HA, Socaciu C (2011). Quantification of carbohydrates in fruit juices using FTIR spectroscopy and multivariate analysis. Spectrosc Int J 26(2):93-104.

Linskens HF, Jackson JF (1988). Wine Analysis, p. 1-8. In: Linskens HF, Jackson JF (Eds). Modern methods of plant analysis. Springer-Verlag, Berlin, Germany.

Lorrain B, Ky I, Pechamat L, Teissedre PL (2013). Evolution of analysis of polyhenols from grapes, wines, and extracts. Molecules 18:1076-1100.

Mateus N, Silva AMS, Vercauteren J, De Freitas V (2001). Occurrence of anthocyanin-derived pigments in red wines. J Agric Food Chem 49(10):4836-4840.

Muccillo L, Gambuti A, Frusciante L, Iorizzo M, Moio L, Raieta K, Rinaldi A, Colantuoni V, Aversano R (2014). Biochemical features of native red wines and genetic diversity of the corresponding grape varieties from Campania region. Food Chem 143:506-513.

Ogbemudia FO, Thompson EO (2014). Variation in plants secondary metabolites and potential ecological roles - a review. Int J Modern Biol Med 5(3):111-130.

Orbán N, Kiss A, Drávucz M, Gál L, Orbán S (2006). Comparative study on selected polyphenol content in red wines of Eger (Hungary). Acta Alim 35(4):465-477.
Ough CS, Amerine MA (1988). Methods for Analysis of Musts and Wines, $2^{\text {nd }}$ Ed. John Wiley \&Sons, New York, 400 p.

Palma M, Barroso CG (2002). Application of FT-IR spectroscopy to the characterisation and classification of wines, brandies and other distilled drinks. Talanta 58(2):265-271.

Patz CD, Blieke A, Ristow R, Dietrich H (2004). Application of FT-MIR spectrometry in wine analysis. Anal Chim Acta 513(1):81-89.

Peña-Neira A, Hernández T, García-Vallejo C, Estrella I, Suarez JA (2000). A survey of phenolic compounds in Spanish wines of different geographical origin. Eur Food Res Technol 210:445-448.

Schulz H, Baranska M (2007). Identification and quantification of valuable plant substances by IR and Raman spectroscopy. Vibrational Spectroscopy 43(1):13-25.

Socaciu C (Ed.) (2008). Food Colorants: Chemical and Functional Properties. CRC Press-Taylor and Francis Group, New York, 633 p.

Somers TC, Verétte E (1988). Phenolic composition of natural wine types, p. 219-257. In: Linskens HF, Jackson JF (Eds.). Wine Analysis. Springer-Verlag, Berlin, Germany.

Soriano A, Pérez-Juan PM, Vicario A, González JM, Pérez-Coello MS (2007). Determination of anthocyanins in red wine using a newly developed method based on Fourier transform infrared spectroscopy. Food Chem 104(3):1295-1303.

Tarantilis PA, Troianou VE, Pappas CS, Kotseridis YS, Polissiou MG (2008). Differentiation of Greek red wines on the basis of grape variety using attenuated total reflectance Fourier transform infrared spectroscopy. Food Chem 111:192-196.

Todaşcă MC, Chira N, Deleanu C, Roşca S (2007). Romanian wine study using IR spectroscopy in comparison with ${ }^{1} \mathrm{H}$ NMR. UPB Sci Bull Series B 69(4):1-8.

Urbano Cuadrado M, Luque de Castro MD, Pérez Juan PM, Gómez-Nieto MA (2005). Comparison and joint use of near infrared spectroscopy and Fourier transform mid infrared spectroscopy for the determination of wine parameters. Talanta 66(1):218-224.

Wilson RH, Tapp HS (1999). Mid-infrared spectroscopy for food analysis: recent new applications and relevant developments in sample presentation methods. Trends Anal Chem 18(2):8593.

Zhang Y-L, Chen J-B, Lei Y, Zhou Q, Sun S-Q, Noda I (2010). Discrimination of different red wine by Fourier-transform infrared and two-dimensional infrared correlation spectroscopy. J Mol Struct 974(1-3):144-150. 